\title{
DESENVOLVIMENTO DE CONSCIÊNCIA FONOLÓ- GICA EM PLA/PLE: análise de material didático e propostas de atividades em tarefas integradas
}

\author{
Luciana Pilatti Telles \\ Universidade Federal do Rio Grande do Sul \\ Luciene Bassols Brisolara \\ Universidade Federal do Rio Grande do Sul
}

\section{RESUMO}

$\mathrm{Na}$ aquisição de uma língua estrangeira, um dos aspectos fundamentais é o desenvolvimento da consciência fonológica do aprendiz, ou seja, é preciso desenvolver a sua capacidade de 'refletir' e 'manipular' os sons da língua (ALVES, 2012). Nesse sentido, o presente estudo propõe-se a analisar um livro didático de português como língua adicional/estrangeira (PLA/PLE), a fim de (1) verificar as oportunidades de desenvolvimento de consciência fonológica no manual e (2) propor atividades de desenvolvimento de consciência fonológica em tarefas integradas. Essas tarefas foram planejadas com o escopo de auxiliar o aprendiz na compreensão do funcionamento da língua e da cultura em aquisição, bem como dos processos variáveis do português do Brasil. A análise do manual é feita com base em ALVES (2012), ALLEGRO (2014), JANOWSKA (2014), TORRESAN (2010), PUREN (2014) e CALABRÒ (2015). Os resultados obtidos permitem-nos concluir que, apesar das oportunidades de elicitação de aspectos fonético-fonológicos que o manual oferece, essas oportunidades estão bastante circunscritas à discriminação auditiva e ao treino de pronúncia, não havendo espaço para discussão de variação fonológica no português falado no Brasil nem propostas de atividades que ajudem o estudante a refletir sobre padrões fonológicos que caracterizam o português brasileiro.

PALAVRAS-CHAVE: Português Língua Adicional/Estrangeira; Consciência Fonológica; Abordagem Orientada para a Ação; Desenvolvimento de Materiais. 


\section{Introdução}

Neste estudo, analisamos oportunidades de desenvolvimento de consciência fonológica de português língua adicional/estrangeira (PLA/ PLE) ${ }^{1}$ no manual Brasil Intercultural (MOREIRA et al., 2013; NASCENTE BARBOSA et al., 2013; BARBOSA et al., 2013) e propomos atividades em tarefas integradas. Para tanto, além das considerações apresentadas por Allegro (2014), sobre o ensino de PLA/PLE em livros didáticos, buscamos analisar, no manual, oportunidades de abordagem a aspectos fonético-fonológicos em suas diferentes unidades, anunciadas em seções próprias de fonologia e em seções de análise linguística de outros níveis gramaticais, como morfossintaxe, semântica e pragmática, nos quais há interação de processos fonológicos sem que esses sejam anunciados. Partindo da análise de atividades de pronúncia ou que visem à consciência fonológica no manual, propomos a integração de tarefas, contextualizadas em projetos pedagógicos. Visamos a responder às seguintes questões: a) A abordagem à pronúncia apresenta-se como conjunto de oportunidades de desenvolvimento de consciência fonológica? b) Na perspectiva de aprendizagem de língua estrangeira orientada à ação, as atividades de percepção sonora e de pronúncia estão integradas e contextualizadas nas unidades didáticas? Há justificativa contextual para a sua apresentação? c) Como contextualizar a fonologia do português em tarefas de português língua adicional/ estrangeira? e d) Como possibilitar o desenvolvimento de consciência fonológica no contexto de PLA/PLE?

Ancoramos nossa análise e proposta em Alves (2012), Allegro (2014), Janowska (2014), Torresan (2010), Puren (2014) e Calabrò (2015) e indicamos possibilidades de desenvolvimento de consciência fonológica como complemento às propostas disponíveis no método em análise. $\mathrm{O}$ artigo está organizado da seguinte maneira: como referencial teórico, apresentamos definições de consciência fonológica em LE, abordagem orientada para a ação e tarefas integradas. Na seção de metodologia, descrevemos os livros da coleção Brasil Intercultural analisados neste estudo. Na seção de análise, descrevemos o estudo desenvolvido por Allegro (2014) e analisamos os livros descritos. Na seção de propostas, apresentamos sugestões de atividades complementares e de tarefa integrada e, por fim, as considerações finais. 


\section{Referencial Teórico}

A aquisição de uma língua estrangeira requer do aprendiz o desenvolvimento de habilidades, dentre elas, aquelas referentes à consciência fonológica, a qual "indica o grau de sensibilidade de uma pessoa à estrutura de sons da língua oral" (ANTHONY et al., 2005, citado em HISMANOGLU, 2011, p.639).

Para Alves (2012), a consciência fonológica envolve a capacidade de 'reflexão' e 'manipulação' dos sons da língua estrangeira. 'Reflexão' pressupõe "notar o inventário de sons da língua-alvo e as diferenças entre os sistemas de sons da L1 e da L2" (ALVES, 2012, p.172) e também envolve a capacidade de o aprendiz perceber os fenômenos que caracterizam a interlíngua, que fazem parte da aquisição de uma LE.

'Manipulação' implica “operar sobre os sons da língua a ser adquirida, através de atividades como as de segmentação, exclusão e transposição de sons, em jogos de linguagem ou em tarefas de consciência fonológica propostas pelo professor" (ALVES, 2012, p.172). É só após serem notadas as diferenças entre os sons da L1 e da L2 que os mesmos poderão ser manipulados.

Conforme Alves (2012) e Venktagiri et al. (2009, citado em HISMANOGLU, 2011, p. 639), há diferentes níveis de consciência fonológica em uma LE, relativos a capacidades de reconhecimento e manipulação: consciência dos padrões silábicos, das rimas, dos fonemas e dos alofones. Esses níveis tendem a apresentar uma ordem de manifestação, sendo que o nível de consciência dos alofones da LE parece manifestar-se de maneira tardia.

Para Torresan (2010), o planejamento de aulas para o desenvolvimento de competências fonético-fonológicas em LE deve prever três momentos: apresentação do input sonoro, prática e reparo dos erros. Para a apresentação do input sonoro, o autor recomenda a exposição dos estudantes a dados orais da língua-alvo, ao uso de transcrições fonológicas, a imagens do aparelho fonador e do sistema articulatório e outros recursos visuais, como barras de escala Cuisinaire e elicitação de gestos articulatórios, além de sensações táteis.

Quanto à prática, classifica-a em dois grupos: exercícios escritos (de transcrição fonológica - em atividades lúdicas - e práticas de reconhecimento), e exercícios orais, como telefone sem fio, ditado entre pares (DAVIS et al., 1988 citado em TORRESAN, 2010, p. 62), ditado coletivo 
(BLANCHE, 2004 citado em TORRESAN, 2010, p. 62), trava-línguas e uso de softwares de dublagem. Para o autor, embora atividades de discriminação fonológica, comparação entre padrões fonológicos e preenchimento de lacunas sejam atividades necessárias, a repetição de exercícios dessas tipologias pode ser desmotivante para os estudantes. Torresan (2010) reconhece a importância do lúdico e do desenvolvimento de "critérios internos" como habilidades metacognitivas.

Com o objetivo de melhorar a produção, é útil fazer com que o estudante desenvolva um critério interno relacionado à realização de um certo fonema, à distribuição dos acentos em uma palavra ou à curva entoacional de um enunciado. Trata-se de uma sensação de apropriação: o aluno sente, de algum modo, que um determinado som corresponde mais do que um outro à língua-alvo. (TORRESAN, 2010, p. 63 [Tradução nossa])

Torresan (2010) considera que autores de manuais de língua e docentes, em geral, dedicam pouca atenção ao ensino dos aspectos fonético-fonológicos da língua-alvo, pois acredita-se que esses conhecimentos são adquiridos de maneira inconsciente. Contrapondo essa ideia, argumenta que é necessário que as atividades de pronúncia sejam planejadas, contextualizadas, dinâmicas e que sejam considerados os estilos de aprendizagem dos estudantes, proporcionando-lhes mais autonomia na aquisição da fonologia da língua-alvo.

Calabrò (2015) também observa que os aspectos fonético-fonológicos recebem tratamento secundário no ensino de L2. Para a autora, é preciso aumentar a consciência dos estudantes sobre as diferenças fonético-fonológicas entre a L1 e a L2. É preciso, também, que os docentes percebam que o ensino da fonologia de uma língua é transversal e contribui para a aprendizagem global de componentes da língua.

Puren (2014) discute noções subjacentes às abordagens em voga nos últimos anos: a abordagem comunicativa e a abordagem orientada para a ação, em destaque desde a proposta do Quadro Europeu Comum de Referência para as Línguas (CONSELHO DA EUROPA, 2001). Segundo a análise de Puren (2014), as duas abordagens são complementares, motivo pelo qual propõe a sua combinação. Na abordagem comunicativa, segundo o pesquisador, ensina-se língua propondo-se situações de interações em viagens turísticas, e todas as interações têm início, meio e fim e não se repetem. $\mathrm{Na}$ abordagem orientada para a ação, o aluno interage em situações cotidianas que podem ser concluídas, mas, também, podem 
ficar suspensas ou repetirem-se. Considerando a abordagem orientada para a ação, Puren (2014), refere-se ao desenvolvimento da competência co-linguística, que é a "capacidade para criar e adotar uma linguagem comum de ação" e da competência co-cultural, que é a "capacidade para criar e adotar uma cultura comum de ação" (PUREN, 2014, p.112). No contexto da abordagem orientada para a ação, está a pedagogia de tarefas.

Janowska (2014, p.63) afirma que a tarefa "concretiza a ativação da competência e mantém uma relação com a ação; as estratégias regulam as ações da linguagem". Há, segundo a autora, três instâncias de tarefas: pedagógicas, autênticas e exercícios de pré-comunicação, que fornecem ao estudante um meio para construir competências de linguagem ajustadas a situações de comunicação. Dessa forma, a tarefa é concebida como uma estratégia para desenvolver competências dos estudantes de uma língua considerando-se situações reais de interação. Nesse contexto, apresentaremos as propostas de tarefas integradas para o desenvolvimento de consciência fonológica.

\section{Metodologia}

Neste estudo, analisamos os materiais dos níveis Básico e Intermediário da coleção Brasil Intercultural e propomos atividades complementares e tarefas integradas com vistas ao desenvolvimento de consciência fonológica.

A coleção Brasil Intercultural: língua e cultura brasileira para estrangeiros, publicada pela editora argentina Casa do Brasil para falantes de espanhol, é constituída de quatro volumes divididos em Ciclo Básico (1 e 2), Ciclo Intermediário (1 e 2), Ciclo Avançado (1 e 2), cada um dos quais composto de livro do aluno e livro de exercícios, com arquivos de áudio disponíveis em http://www.brasilintercultural.com.ar/, e manual do professor, em formato digital, também disponível na página. Segundo os autores, a coleção tem como foco a abordagem pedagógica intercultural, considerando a sala de aula como um espaço de interação, de contato entre diferentes línguas e culturas.

\section{Análise}

Nesta seção, apresentaremos a análise realizada por Allegro (2014) e a nossa análise dos dois primeiros volumes da coleção Brasil Intercultural. 


\subsection{Análise da coleção Brasil Intercultural - Allegro (2014)}

Allegro (2014) analisou um conjunto de manuais de PLA/PLE, dentre os quais, os volumes da coleção Brasil Intercultural. Quanto ao sumário dos volumes do manual Brasil Intercultural, destacou a informação do lugar da abordagem de aspectos fonético-fonológicos: no volume concernente aos Ciclos 1 e 2, as seções intituladas "Pontos de partida" e "Análise linguística"; no volume destinado aos Ciclos 3 e 4, "Análise linguística". A autora observa a disponibilidade de quadros de consoantes e vogais, ditongos e dígrafos ao final de cada volume. Essas seções em apêndice são intituladas "Fonética".

Nas unidades didáticas do manual, Allegro (2014) analisou as oportunidades de exercícios de fonética e fonologia e de compreensão de áudio. Reportamos, no Quadro 1, um resumo dos dados apresentados por Allegro (2014), referentes às seções destinadas à elicitação de elementos fonético-fonológicos no manual.

\begin{tabular}{|l|l|l|}
\hline $\begin{array}{l}\text { Unidade didá- } \\
\text { tica }\end{array}$ & Constituinte & Metodologia \\
\hline $\begin{array}{l}\text { 1 a 7 (Livro 1) } \\
1 \text { a 4 (Livro 2) }\end{array}$ & $\begin{array}{l}\text {-Vogais orais, glide velar, } \\
\text { vogal central nasalizada, } \\
\text { consoantes [s], [z], frica- } \\
\text { tivas e africadas alveopa- } \\
\text { latais, [l], [r], [b] e [v]. } \\
\text {-Ditongo nasal posterior. }\end{array}$ & $\begin{array}{l}\text {-Discriminação auditiva; } \\
\text {-busca de exemplos para os } \\
\text { sons em análise; } \\
\text {-discriminação auditiva e } \\
\text { anotação de particularida- } \\
\text { des de pronúncia do /r/ em } \\
\text { diferentes localidades; } \\
\text {-pronúncia de palavras reti- } \\
\text { radas de textos. }\end{array}$ \\
\hline 7 (Livro 1) & Acento & $\begin{array}{l}\text {-Descrição de regra de acen- } \\
\text { tuação. }\end{array}$ \\
\hline
\end{tabular}

Quadro 1: Unidades, constituintes abordados e metodologia empregada nas seções destinadas à análise fonético-fonológica (adaptado de ALLEGRO, 2014, p. 140) 
Referente aos exercícios de compreensão oral, Allegro (2014) apresenta em quadros exemplares de gêneros textuais orais e escritos explorados através de exercícios de preenchimento de lacunas, anotação de informações e produção de respostas a perguntas.

Adaptamos de Allegro (2014) o quadro de análise de manuais de PLA/PLE. Selecionamos apenas as informações referentes aos manuais da coleção Brasil Intercultural. Conforme veremos, a autora reconhece atendimento, na proposta do manual, à maioria dos critérios por ela considerados, inclusive aos critérios (C) e (G).

\begin{tabular}{|l|l|l|l|l|l|l|l|}
\hline A & B & C & D & E & F & G & H \\
\hline $\begin{array}{l}\text { Não } \\
\text { cum- } \\
\text { pre. }\end{array}$ & Cumpre. & Cumpre. & Cumpre. & Cumpre. & Cumpre. & Cumpre. & $\begin{array}{l}\text { Não } \\
\text { cum- } \\
\text { pre. }\end{array}$ \\
\hline
\end{tabular}

Legenda:

A) menção da abordagem fonética na introdução;

B) menção, no sumário, de exercícios de fonética;

C) explicação e/ou sistematização do uso do som;

D) utilização do alfabeto fonético;

E) exercícios para treinar a produção ou percepção de segmentos fônicos ou de elementos prosódicos;

F) exercícios que trabalhem oralidade a partir da repetição ou compreensão de estímulos orais;

G) integração do exercício aos demais exercícios da unidade;

H) sugestão de recursos, ferramentas ou tecnologias de fala disponíveis na atualidade.

Quadro 2: Cumprimento de critérios (Adaptado de ALLEGRO, 2014, p. 146, Quadro 21)

Passaremos a seguir à análise por nós desenvolvida, em busca da avaliação das oportunidades de desenvolvimento de consciência fonológica no manual e da integração de seus exercícios.

\subsection{Análise da Coleção Brasil Intercultural}

Analisamos livros-texto, livros de exercícios e manual do professor referentes aos ciclos 1, 2, 3 e 4 dos ciclos Básico e Intermediário da coleção. Nesses volumes, analisamos não somente os exercícios das seções 
destinadas à elicitação de elementos fonético-fonológicos, mas também as oportunidades de desenvolvimento de consciência fonológica em exercícios referentes a outros componentes gramaticais. No Quadro 3, temos a síntese das atividades disponíveis no primeiro livro-texto, com indicação concernente à disponibilidade de áudio.

\begin{tabular}{|c|c|c|}
\hline $\begin{array}{l}\text { Uni- } \\
\text { dade }\end{array}$ & Atividades & $\begin{array}{l}\text { Disponibi- } \\
\text { lidade de } \\
\text { áudio }\end{array}$ \\
\hline 1 & $\begin{array}{l}\text { Discriminação auditiva de vogais anteriores e poste- } \\
\text { riores no interior e em final de palavra. Exemplos: } \\
\text { namoro, sorte, feriados, veneno, qualquer, cidade. } \\
\text { Há símbolos fonéticos, mas não há reflexão sobre } \\
\text { processos fonológicos. }\end{array}$ & Sim. \\
\hline 2 & $\begin{array}{l}\text { Leitura e identificação de exemplos com }[\mathrm{s}],[\mathrm{z}] \text {, } \\
\text { [1] e [w]. Não há exercício prévio de percepção dos } \\
\text { sons em análise. }\end{array}$ & Não. \\
\hline 3 & $\begin{array}{l}\text { Audição de diálogo com posterior releitura do texto } \\
\text { e busca por exemplos com africadas alveopalatais. } \\
\text { Não há orientações para percepção de regra variá- } \\
\text { vel. }\end{array}$ & Sim. \\
\hline 4 & $\begin{array}{l}\text { Audição prévia de Aquarela, de Toquinho, Viní- } \\
\text { cius de Moraes, G. Marra e M. Fabrizio, seguida de } \\
\text { orientação para busca, no texto escrito, de exemplos } \\
\text { para os sons [b] e [v]. }\end{array}$ & $\begin{array}{l}\text { Não para a } \\
\text { atividade } \\
\text { de fonéti- } \\
\text { ca. }\end{array}$ \\
\hline 5 & $\begin{array}{l}\text { Exercício sobre fricativas alveopalatais no qual o } \\
\text { estudante deve organizar em um quadro as palavras } \\
\text { retiradas do texto de abertura da unidade. A seleção } \\
\text { deve ser feita considerando a disponibilidade, nas } \\
\text { palavras, dos segmentos em análise e sua classifica- } \\
\text { ção quanto ao estado da glote. }\end{array}$ & Não. \\
\hline
\end{tabular}




\begin{tabular}{|l|l|l|}
\hline 6 & $\begin{array}{l}\text { Na página de abertura, há o texto intitulado Tudo } \\
\text { por um flash, de Eliane Lobato. O exercício de reco- } \\
\text { nhecimento de sons objetiva a percepção da relação } \\
\text { grafema/fone. Há palavras grafadas com "x", e o } \\
\text { estudante deve classificá-las conforme o som repre- } \\
\text { sentado pelo grafema. Não é considerada a variação } \\
\text { geográfica. }\end{array}$ & Não. \\
\hline 7 & $\begin{array}{l}\text { Quadro de acento ortográfico e lista de heterotôni- } \\
\text { cos. Não há oportunidades de reflexão ou de genera- } \\
\text { lizações sobre acento fonológico. }\end{array}$ & Não. \\
\hline
\end{tabular}

Quadro 3: Exercícios de fonética, com ou sem áudio, Livro 1.

Conforme expresso no Quadro 3, ainda que haja exercícios identificados como atividades de fonética em todas as unidades, não há áudio disponível para todas. Vemos, nas informações grifadas no quadro, a indicação de que faltam oportunidades de reflexão sobre a ocorrência dos sons em análise. No Quadro 4, passamos ao resumo da análise dos exercícios de fonética no segundo livro-texto da coleção Brasil Intercultural.

\begin{tabular}{|c|c|c|}
\hline $\begin{array}{l}\text { Unida- } \\
\text { de }\end{array}$ & Atividades & $\begin{array}{l}\text { Disponibilida- } \\
\text { de de áudio }\end{array}$ \\
\hline 1 & $\begin{array}{l}\text { Atividades sobre vogais médias posteriores } \\
\text { orais. Há um parágrafo cujas palavras estão } \\
\text { com o grafema "o" grifado. O estudante deve } \\
\text { organizar no quadro as palavras quanto à } \\
\text { abertura das vogais. Não há exemplos de } \\
\text { palavras com abaixamento. }\end{array}$ & Não. \\
\hline 2 & $\begin{array}{l}\text { Audição da música Sutilmente, da banda Skank } \\
\text { seguida de solicitação de organização de pa- } \\
\text { lavras com o grafema "e" em um quadro, } \\
\text { conforme som: [e] ou [i]. Os dados são de } \\
\text { alçamento de átona final e de harmonia vo- } \\
\text { cálica, mas não há reflexão sobre processos. }\end{array}$ & $\begin{array}{l}\text { Não especifi- } \\
\text { camente para } \\
\text { a atividade. }\end{array}$ \\
\hline
\end{tabular}




\begin{tabular}{|l|l|l|}
\hline 3 & $\begin{array}{l}\text { Ortografia: dígrafos para a representação } \\
\text { de }[\mathbf{s}] .\end{array}$ & Sim. \\
\hline 6 e 8 & $\begin{array}{l}\text { Sotaques no Brasil e diferenças fonéticas entre } \\
\text { países lusófonos. O estudante deve anotar as } \\
\text { suas impressões; não há orientações relati- } \\
\text { vas a constituintes fonológicos. }\end{array}$ & Sim. \\
\hline
\end{tabular}

Quadro 4: Exercícios de fonética, com ou sem áudio, Livro 2.

No Quadro 4, observamos a disponibilidade de exercícios de fonética em quase todas as unidades do segundo livro da coleção. Conforme grifamos, ainda que sejam abordados elementos de variação fonológica, não há orientação para a observação nem de variantes nem de condicionadores. Na primeira unidade, no exercício referente à abertura de vogais médias, não há áudio disponível.

Nos dois livros de exercícios, também há seções de fonética (identificadas nos livros e níveis), embora em menor quantidade, conforme observamos no Quadro 5.

\begin{tabular}{|l|l|l|}
\hline Unidade & Atividade & $\begin{array}{l}\text { Disponibi- } \\
\text { lidade de } \\
\text { áudio }\end{array}$ \\
\hline 3 & Discriminação auditiva: [a] e [ã]. & Sim. \\
(N1, L1) & $\begin{array}{l}\text { Discriminação de [s] e [z] em palavras grifadas } \\
\text { no texto da canção "Garota de Ipanema", de Tom } \\
\text { e Vinícius. }\end{array}$ & $\begin{array}{l}\text { Orienta - } \\
\text { ção para } \\
\text { audição da } \\
\text { canção. }\end{array}$ \\
\hline 1 & $\begin{array}{l}\text { Discriminação auditiva de [b] e [v] em lista de } \\
\text { palavras. }\end{array}$ & Sim. \\
\hline (N2, L1) & $\begin{array}{l}\text { Discriminação de fricativas alveopalatais. O } \\
\text { exercício indica fonema, mas os símbolos estão } \\
\text { entre colchetes. }\end{array}$ & Sim. \\
\hline 2 \\
(N2, L1)
\end{tabular}




\begin{tabular}{|c|c|c|}
\hline $\begin{array}{l}3 \\
(\mathrm{~N} 2, \mathrm{~L} 1)\end{array}$ & $\begin{array}{l}\text { Discriminação de fricativa alveopalatal não } \\
\text { vozeada e de }[\mathrm{s}],[\mathrm{z}] \text { e }[\mathrm{ks}] \text {. O exercício indica } \\
\text { fonema, mas os símbolos estão entre colchetes. } \\
\text { Está anunciado "treino de fonética da letra x". }\end{array}$ & Sim. \\
\hline $\begin{array}{l}4 \\
(\mathrm{~N} 2, \mathrm{~L} 1)\end{array}$ & $\begin{array}{l}\text { Ditado de heterotônicos. Nesse exercício, a sílaba } \\
\text { tônica deve ser sublinhada. Algumas palavras } \\
\text { terminam em ditongo, mas não há indicação } \\
\text { de generalização. }\end{array}$ & Sim. \\
\hline 1 (L2) & $\begin{array}{l}\text { Coleta de palavras com ditongos nasais [ẽj] e } \\
\text { [ãw] na canção Hoje eu vou pagodear, da banda } \\
\text { Fundo de Quintal. }\end{array}$ & $\begin{array}{l}\text { Orienta- } \\
\text { ção para } \\
\text { audição da } \\
\text { canção. }\end{array}$ \\
\hline 4 (L2) & $\begin{array}{l}\text { Discriminação auditiva de [s] e [z] e prática } \\
\text { de pronúncia com a canção Gentileza, de Marisa } \\
\text { Monte. }\end{array}$ & $\begin{array}{l}\text { Orienta- } \\
\text { ção para } \\
\text { audição da } \\
\text { canção. }\end{array}$ \\
\hline 6 (L2) & $\begin{array}{l}\text { Orientação para, após discussões em aula sobre } \\
\text { fenômenos linguísticos, reescrita de palavras } \\
\text { da canção Tiro ao álvaro, de Adoniran Barbo- } \\
\text { sa, conforme norma culta padrão. }\end{array}$ & $\begin{array}{l}\text { Orienta- } \\
\text { ção para } \\
\text { audição da } \\
\text { canção. }\end{array}$ \\
\hline 7 (L2) & $\begin{array}{l}\text { Comparação entre pronúncias "brasileira" e } \\
\text { "portuguesa". Não há orientações a respeito de } \\
\text { processos fonológicos ou de transcrição. }\end{array}$ & Sim. \\
\hline
\end{tabular}

Quadro 5: Exercícios de fonética, livros de exercícios.

No Quadro 5, referente às atividades de fonética nos livros de exercícios, vemos o predomínio de atividades de discriminação auditiva e exercícios de relação grafema/ fone. Na Unidade 6 do segundo livro, há a solicitação de reescrita de palavras da canção Tiro ao Álvaro, de Adoniran Barbosa e, na Unidade 7, a comparação entre pronúncias de falantes brasileiros e portugueses.

Analisamos as seções de fonética e outras seções de análise linguística, em busca de oportunidades de desenvolvimento de consciência fo- 
nológica. Encontramos espaços nos quais essas oportunidades poderiam ter sido aproveitadas. No primeiro livro, por exemplo, na síntese referente à flexão verbal, há os mesmos ditongos nasais na conjugação de terceira pessoa do plural no pretérito perfeito e no futuro do presente; a diferença está na sílaba acentuada. Além dos grifos para morfemas, poderia haver condução à reflexão relativa ao acento lexical. Outra oportunidade estaria na análise do plural de nomes e adjetivos. Na página 44, indica-se "o homem/ os homens", sem oportunidade de observação da formação de ditongo nasal. No segundo volume, como vimos nos quadros, tanto no livro-texto quanto no livro de exercícios, há abordagem à variação linguística. Faltam, contudo, ferramentas de análise de variação fonológica para além da percepção de "sotaque". As seções de fonética, de modo geral, são destinadas à discriminação auditiva de segmentos e, algumas vezes, ao reconhecimento de relação grafema/ fone.

Devemos observar que encontramos, em uma seção de análise de outros componentes gramaticais, uma oportunidade de acesso a regras fonológicas bem-aproveitada. No Livro 2, na página 51, a apresentação da alomorfia do sufixo de diminutivo (-inho/-inha, -zinho/-zinha) está amparada pela análise de padrões fonológicos.

No que se refere aos exercícios de fonética, no manual do professor, no Ciclo Básico, recomenda-se, na Unidade 0, que o professor apresente um panorama de cada região, com relação às diferenças de sotaques, para que os alunos percebam que, no Brasil, há diferenças fonéticas relacionadas a cada região do país. Ainda na mesma unidade, sugere-se que o professor estabeleça diferenças e semelhanças entre os sons da língua materna do aprendiz e da língua estrangeira. Na Unidade 3, indica-se que serão trabalhados sons nasais e os sons [ $\left.\mathrm{t} \int \mathrm{i}\right]$ e [d3i]. Na unidade 5 , trata-se das diferenças fonéticas entre os pares [s] e [z]. Na Unidade 6, é informado que será estudada a fonética da letra " $x$ ", contrastando-se $o$ português com o espanhol.

No manual do professor do Ciclo Intermediário, as informações sobre fonética estão nas unidades 2 e $6 . \mathrm{Na}$ unidade 2 , informa-se que serão estudadas as diferenças fonéticas entre os pares [e] e [i]. Na unidade 6, cita-se abordagem a sotaques do Brasil e à noção de prestígio. Vemos que, nos manuais destinados aos professores, há a indicação de tópicos a serem trabalhados, mas não há orientações metodológicas ou explicitação dos objetivos referentes à abordagem aos aspectos fonético-fonológicos selecionados. 
Tendo analisado os volumes do Brasil Intercultural referentes ao Ciclo Básico e ao Ciclo Intermediário, passaremos à análise de uma unidade didática do primeiro livro-texto, e proporemos atividades complementares a essa unidade, além de tarefas independentes do uso do manual.

A Unidade 7 do primeiro livro-texto, "Túnel do Tempo", está dividida em dois blocos: "Outrora" e "Cápsula do tempo". Na abertura do primeiro bloco, na página 115 , temos a solicitação de leitura da crônica Versões, de Luis Fernando Verissimo, seguida por três questões para discussão do texto. Na página seguinte, dois exercícios de análise linguística, em que se pede a substituição de expressões retiradas do texto por outras de mesmo sentido e, no último exercício, que se observem três palavras retiradas do texto: "príncipe", "experiência" e "você", identificadas, respectivamente, como proparoxítona, paroxítona e oxítona.

A observação de sílabas acentuadas segue nas páginas 117 e 118, com um quadro de regras e exemplos de acentuação gráfica, no qual há informações sobre proparoxítonas, paroxítonas, oxítonas, monossílabos tônicos, hiatos com "i" e "u" e ditongos abertos. Na página 118, temos listas de palavras em português e espanhol para percepção dos heterotônicos, como "academia", paroxítona, em português e em espanhol, com a diferença de que a sílaba tônica em espanhol é "de" e em português é “mi”. Nessa mesma página, é solicitado um exercício de escrita de um final de história para o sapo, personagem da crônica de Verissimo. O estudante deve usar, no mínimo, cinco heterotônicos. Poderíamos ver aqui uma oportunidade de exercício e de desenvolvimento de "critérios internos" relacionados aos padrões de acentuação do PLA/PLE, mas as regras expostas no quadro são concernentes à acentuação gráfica somente, e os heterotônicos da lista apresentam diferença de acentuação gráfica apenas entre algumas palavras, como entre "atmosfera" e "atmósfera".

Ainda com foco na acentuação gráfica, há, na página 119, a solicitação de leitura e de acentuação das palavras do texto Anos 60 - A época que mudou o mundo, de Cláudia Garcia. Há, na sequência, três exercícios para discussão a partir dos sentidos do texto.

Ainda no primeiro bloco, nas páginas 120 e 121, há vocabulário, contextualizado no texto de Claudia Garcia, relativo às roupas femininas e masculinas, reempregado no exercício da página 122. Nesse exercício, o estudante deve descrever as roupas que usaria em diferentes situações. Na página 123, o estudante é chamado a pesquisar sobre as décadas de 70, 80 e 90 quanto a moda, comportamento, situação sociopolítica e íco- 
nes de cada época, para apresentação dos dados coletados à turma, com posterior produção de relato considerando uma viagem a uma das décadas analisadas.

As atividades do primeiro bloco estão relacionadas contextualmente, e há importantes oportunidades de interação entre pares, sem a indicação prévia de um diálogo estruturado ou semiestruturado para produções orais (o que nos aproxima da abordagem orientada para ação). Com relação ao acento, contudo, vemos que foi perdida a oportunidade de reflexão sobre padrões de organização do acento no português e no espanhol, pois todos os exercícios são de ortografia.

No segundo bloco da Unidade 7, há outro texto cujas palavras devem ser acentuadas pelo estudante. O texto é Buenos Aires cria cápsula do tempo para ser aberta no ano de 2210 e foi publicado na versão digital do jornal Folha de São Paulo. Há, na mesma página, questões para discussão a partir da leitura do texto. Ainda referente a essa temática, na página 125, há um exercício de leitura de reportagem do programa televisivo Fantástico sobre a cápsula do tempo, em áudio e vídeo, com posterior solicitação de produção, em trios, de mensagens para uma cápsula do tempo para ser aberta daqui a cem anos.

Na perspectiva de projeções para o futuro, na página 126, há proposta de leitura de um texto multimodal composto por três quadros com promessas para 2012, 2013 e 2014. No último deles, a meta é não fazer mais promessas. A partir da leitura, os estudantes devem discutir os sentidos do texto e as práticas de planejamento de metas para o novo ano em sua cultura. Devem também se posicionar quanto à importância da prática de planejamento, bem como fazer planos, a curto, médio e longo prazo. Na mesma temática de planejamento, na página 127, os estudantes devem discutir, a partir da definição de José Martí, a ideia de atingimento de objetivos pelos seres humanos. Nessa página, passa-se ao exercício de preenchimento de lacunas com as expressões idiomáticas que estão dispostas em um quadro. A unidade é encerrada com a canção Tempos Modernos, de Lulu Santos. Há exercício de preenchimento de lacunas com palavras que tenham ditongos nasais. Não há, nessa, que é a última unidade do volume, nem orientações referentes às vogais nasalizadas nem aos ditongos nasais.

Tematicamente, como vimos, as propostas parecem bastante contextualizadas. Embora questões do âmbito da fonologia estejam presentes, são pouco exploradas, alcançando apenas, considerando-se a proposta 
de Torresan (2010), o momento de compreensão, com exercícios de tipologias bastante recorrentes, como preenchimento de lacunas, sem oferta de oportunidades de desenvolvimento de consciência fonológica.

\section{Propostas de atividades complementares e de tarefas integradas}

Nesta seção, apresentamos sugestões de atividades complementares aos manuais analisados, a fim de contribuir para o desenvolvimento de consciência fonológica de estudantes de PLA/PLE. Apresentamos uma tarefa para ser desenvolvida independentemente do uso do manual.

Para desenvolver a consciência fonológica com relação ao acento, o professor pode usar o "telefone fonético", artefato bastante semelhante a um telefone convencional, feito com um pedaço de cano de PVC e dois "joelhos", também de PVC. Considerando o caso de falantes nativos de espanhol aprendendo português, o professor pode solicitar aos estudantes que leiam a palavra 'democracia' em espanhol e, após, em português. Com o uso do "telefone fonético", o som é amplificado, e o aluno pode prestar mais atenção nas duas produções, evidenciando, para o espanhol, a formação do ditongo 'ia', enquanto para o português, a produção de hiato.

Outro recurso que pode ser utilizado é a Escala Cuisinaire, desenvolvida por Emile-Georges Cuisinaire (1891-1980), para ensinar conceitos de matemática. Torresan (2010) sugere seu uso no contexto linguístico. Através dela, podemos trabalhar a consciência fonológica com relação a aspectos como acento e sílaba. Pode-se escolher um poema, por exemplo, Aqui, de Paulo Leminsky, e solicitar aos estudantes que façam a sua recitação utilizando o "telefone fonético". É interessante esclarecer aos estudantes que, através da leitura do poema, serão exemplificadas regras de sílaba e de acento. Os alunos, organizados em pequenos grupos, devem receber barras da Escala Cuisinaire de tamanhos diferentes para que, através de seu uso, segmentem em sílabas as palavras do poema. Para escandir a palavra 'aqui', por exemplo, os alunos usarão, inicialmente, duas barrinhas iguais, para mostrar que há duas sílabas. Posteriormente, para identificar a sílaba tônica, usarão uma barrinha maior. Neste caso, a primeira barrinha será menor do que a segunda, identificando que a tonicidade de 'aqui' está na última sílaba.

Através de atividades com canções, podemos abordar expressões idiomáticas como frases que dão visibilidade a processos fonológicos 
emergentes entre palavras. Sugerimos a didatização da canção Aprendendo a jogar, de Guilherme Arantes. Inicialmente, deve-se buscar, com os alunos, expressões idiomáticas em suas línguas. Após a análise das expressões e da canção, passa-se à exploração de seus aspectos fonético-fonológicos. Previamente, o professor pode gravar algumas expressões da música com diferentes junturas externas e desenvolver oportunidades de análise de regras prosódicas, como processos de sândi externo em português, como ditongação, elisão e degeminação. Na frase "Água mole em pedra dura tanto bate até que fura", pode haver degeminação (mol[e] $\mathrm{m}$ ou mol[i]m) ou ditongação (mol[je]m, bat[ja]té), mas não ocorrerá elisão (bat[a]té), já que este processo só ocorre quando, em uma sequência de vogais, a seguinte é posterior (BISOL, 1992). Ao final da atividade, pode-se fazer uma comparação entre a língua do aprendiz e o português, para que se observe se os processos de sândi ocorrem.

Ainda com canções, é possível analisar segmentos em palavras. Através da didatização da canção Capitu, de Luiz Tatit, por exemplo, podemos analisar contextos para ocorrência de fricativa velar, fricativa glotal e de tepe, conforme distribuição dos sons nas sílabas das palavras. Após a contextualização da personagem, passa-se à audição da música cantada por seu compositor. Em seguida, os alunos recebem fichas com trechos da canção, os quais apresentam contextos para fricativa velar e para tepe, para leitura individual no telefone fonético. Para o passo seguinte, é necessário que os estudantes tenham orientações referentes a símbolos fonéticos e às diferenças entre gestos articulatórios para a realização desses segmentos. Sugerimos o uso de figura do aparelho fonador em corte sagital, disponível em SILVA \& YEHIA (2009), ou o uso da câmera do celular ou de espelho para visualizar os seus gestos articulatórios na produção dessas consoantes. Terminadas as explicações sobre os sons-alvo da tarefa, passa-se ao jogo da memória de contextos e segmentos. Nesse jogo, as fichas têm palavras com lacunas a serem preenchidas com os símbolos dos sons-alvo (disponibilizados em cartinhas), conforme contexto, como em "a_dente" (ardente). Após a realização do jogo da memória, com apoio na pronúncia de Luiz Tatit, em Capitu, é importante que se passe a um exercício de síntese, com o objetivo de registro da manipulação consciente de informações dos segmentos em análise e de sua distribuição na sílaba.

Para abordar o tema da variação fonológica em português, pode-se ouvir, também, a canção Capitu, interpretada por Ná Ozzetti, com poste- 
rior observação de contextos de variação fonológica.

As questões relativas à variação também podem ser exploradas em entrevistas, como aquela feita ao músico Kleiton Ramil, da dupla Kleiton e Kledir, no programa radiofônico Então, foi assim. O professor pode entregar aos estudantes a transcrição ortográfica de um fragmento da entrevista, executar o áudio e, após discussão do texto, solicitar atenção à pronúncia das vogais /e/ e /o/. Nem sempre "e" e "o" são pronunciados como [e] e [o]. Temos, então, o contexto para síntese da observação de que, em português, as vogais /e/ e /o/ podem ser pronunciadas como [e] e [o], mas, também, como [i] e [u], uma variação que tem, como um dos fatores linguísticos intervenientes, a atonicidade (BISOL, 1981; VIEIRA, 2010), pois vogais átonas ficam propensas à variação, enquanto vogais tônicas são preservadas.

As atividades ora descritas foram testadas em duas oportunidades: em uma oficina destinada a professores de LE em formação ou já atuantes e em uma aula destinada a estudantes uruguaios intercambistas. $\mathrm{Na}$ aula, trabalhamos com a tarefa de entrevistas radiofônicas ou televisivas, contextualizadas a partir de levantamento de informações, junto aos estudantes, sobre músicos brasileiros que conheciam. Houve exercícios de compreensão de entrevistas a Maria Rita, pela Trip FM, e a Elis Regina, concedida ao programa TV Mulher. Tendo o propósito e o suporte, buscamos pelas ferramentas linguísticas necessárias, dentre as quais, elementos fonológicos que poderiam ser relevantes. Passamos então, à atividade com a canção de Guilherme Arantes, gravada por Elis Regina, desenvolvida tal como a descrevemos na sugestão. Estávamos em um laboratório de línguas, com equipamentos à disposição, o que possibilitou o desenvolvemos da tarefa de entrevista com efeitos de entrevista radiofônica. A realização dessa tarefa integrou compreensão de textos orais e escritos, produção de texto oral (entrevista) e escrito (tomar notas durante a execução das entrevistas a Maria Rita e a Elis Regina) e ofereceu oportunidades de desenvolvimento de consciência fonológica sobre regras prosódicas do português falado no Brasil. 


\section{Considerações finais}

Com o presente estudo, buscamos analisar as oportunidades de desenvolvimento de consciência fonológica nos dois primeiros volumes da coleção Brasil Intercultural e propor exercícios complementares ao manual analisado e tarefas integradas.

A partir da análise do Ciclo Básico e Intermediário da coleção Brasil Intercultural, foi possível verificar a necessidade da complementação do manual com atividades diversificadas que se constituam em oportunidades de desenvolvimento de consciência fonológica pelo estudante, para que, nas palavras de Torresan (2010), o aprendiz desenvolva "critérios internos", não ficando restrito a exercícios tradicionais de compreensão, como os de discriminação auditiva. Entendemos que a complementação de unidades do livro com atividades como aquelas que propusemos, que podem integrar compreensão e produção de textos orais e escritos (em tarefas, com definição de propósitos e de interlocutores) pode atender, além do objetivo de desenvolvimento de consciência fonológica, ao objetivo de consciência sociolinguística, pela análise, reflexão e manipulação de regras variáveis do português falado no Brasil. 


\section{DEVELOPMENT OF PHONOLOGICAL AWARENESS IN PAL / PFL: analysis of didactic material and pro- posed activities in integrated tasks}

\section{ABSTRACT}

In the acquisition of a foreign language, one of the fundamental aspects is the development of learner's phonological awareness, that is, one must develop their ability to 'think about' and 'manipulate' the sounds of language (ALVES, 2012). In this sense, the present study aims at analyzing a textbook of Portuguese as an additional / foreign language (PLA / PLE), in order to (1) verify opportunities for phonological awareness development in the manual and (2) propose activities for the development of phonological awareness in integrated tasks. These tasks were planned with the scope of assisting the learner in understanding the functioning of the language and culture in acquisition, as well as the variable processes of Brazilian Portuguese. The analysis of the manual is based on Alves (2012), ALLEGRO (2014), JANOWSKA (2014), TORRESAN (2010), PUREN (2014), CALABRÒ (2015). The obtained results allow us to conclude that, despite the opportunities for eliciting phonetical and phonological aspects that the manual offers, these opportunities are very limited to auditory discrimination and pronunciation training, and there is neither room for discussion of phonological variation in Portuguese spoken in Brazil, nor any proposals for activities that help the student to think about phonological patterns that characterize Brazilian Portuguese.

KEYWORDS: Portuguese as an Additional/ Foreign Language; Phonological Awareness; Task-based Approach; Development of Didactic Materials.

NOTA

${ }^{1}$ Os termos 'Língua Estrangeira', L2' e 'Língua Adicional ', neste texto, são utilizados intercambiavelmente assim como os termos 'Língua Materna' e 'L1'. 


\section{REFERÊNCIAS}

ALLEGRO, F.R.P. Ensino de pronúncia de português língua estrangeira: análise de livros didáticos. Tese (Doutorado em Letras). São Paulo: PUCSP, 2014.

ALVES, U. K. "A explicitação dos aspectos fonético-fonológicos da L2: teoria e pesquisa na sala de aula". In: LAMPRECHT, R. R. et al. Consciência dos sons da língua: subsídios teóricos e práticos para alfabetizadores, fonoaudiólogos e professores de língua inglesa. 2. ed. Porto Alegre: EdiPUCRS, 2012, p. 211-230.

BISOL, L. Harmonia vocálica: uma regra variável. Tese (Doutorado em Linguística) - UFRJ, Rio de Janeiro, 1981.

BISOL, L. Sândi vocálico externo: degeminação e elisão. Cadernos de Estudos Linguísticos, Campinas, (23): 83-101, Jul/Dez. 1992.

CALABRÒ, L. Il Workshop di Fonetica in Italiano L2/LS. In: Italiano LinguaDue, n.1, 2015.

CONSELHO DA EUROPA. Quadro Europeu Comum de Referência para as Línguas. Porto: ASA Editores II, 2001.

GODINHO, R.; RAMIL, K. Maria Fumaça. Disponível em: < $\underline{\text { http://www.abra- }}$ video.org.br/p5147.aspx> $>$. Acesso em 15 de março de 2017.

HISMANOGLU, M. An investigation of phonological awareness of prospective EFL teachers. Procedia - Social and Behavioral Sciences, 31,p. 639 - 645, 2012.

JANOWSKA, I. Tarefa: um conceito-chave da perspectiva acional Tradução de Eduardo Nadalin e José Carlos Moreira. In: Revista X. vol.4. Dossiê Especial Didática sem Fronteiras. Paraná: UFPR, 2014.

MOREIRA, A. et al. Brasil Intercultural - Língua e cultura brasileira para estrangeiros. Ciclo Básico, níveis 1 e 2. Buenos Aires: Editora Casa do Brasil, 2013.

NASCENTE BARBOSA, C. N. et al. Brasil Intercultural: língua e cultura brasileira para estrangeiros. Ciclo Básico, livro de exercícios, níveis 1 e 2. Buenos Aires: Editora Casa do Brasil, 2013.

NASCENTE BARBOSA, C. N. et al. Brasil Intercultural: língua e cultura brasileira para estrangeiros. Ciclo intermediário, níveis 3 e 4. Buenos Aires: Editora Casa do Brasil, 2013.

NASCENTE BARBOSA, C. N. et al. Brasil Intercultural: língua e cultura brasileira para estrangeiros. Ciclo intermediário, livro de exercícios, níveis 3 e 4. Buenos Aires: Casa do Brasil, 2013.

OZZETTI, N. Capitu. São Paulo: Records, 2004.

PUREN, C. Enfoque comunicativo versus enfoque orientado a la acción social. 
In: Les Cahiers du GERES n ${ }^{\mathbf{7}}$, Actes de la XIIème Rencontre Internationale du GÉRES «Léspagnol et le monde du travail», Metz, 19-21 juin 2014, p.104120, Disponível em: <http:www.geres-sup.com/cahiers/cahiers-du-geres-n-7-1/>. Acesso em: 12 de dezembro de 2016.

CRISTÓFARO-SILVA, T. ; YEHIA, H. C. Sonoridade em Artes, Saúde e Tecnologia. Belo Horizonte: Faculdade de Letras, 2009. Disponível em <http://fonologia.org>. Acesso em 11 de maio de 2018.

TATIT, L. Capitu. São Paulo: Dabliú Discos, 2007.

TORRESAN, P. Didattica per lo sviluppo della competenza fonetico-fonologica in lingua Straniera. In: Entre Lenguas. v.15, jan.-dez., 2010.

VIEIRA, M. J. B. As vogais médias átonas nas três capitais do sul do Brasil. In: Leda Bisol; Gisela Collischonn. (Org.). Português do sul do Brasil: variação fonológica. Porto Alegre: EdiPUCRS, 2010, p. 50-72.

Recebido: $12 / 05 / 2018$

Aceito: 14/09/2018 